\title{
An Investigation into the Reasoning of Pre-Service Integrated Science Teachers When Classifying Matter into Elements and Compounds
}

\author{
Nathaniel A. Omilani, Mabel I. Idika \\ Department of Science and Technology Education, University of Ibadan, Ibadan, Nigeria \\ Email: ayonath2002@gmail.com
}

How to cite this paper: Omilani, N. A., \& Idika, M. I. (2020). An Investigation into the Reasoning of Pre-Service Integrated Science Teachers When Classifying Matter into Elements and Compounds. Creative Education, 11, 2512-2522.

https://doi.org/10.4236/ce.2020.1112184

Received: September 29, 2020

Accepted: December 6, 2020

Published: December 9, 2020

Copyright $\odot 2020$ by author(s) and Scientific Research Publishing Inc. This work is licensed under the Creative Commons Attribution International License (CC BY 4.0).

http://creativecommons.org/licenses/by/4.0/

\begin{abstract}
This study investigated the reasoning of pre-service integrated science teachers when they categorized matter into elements and compounds. The study adopted a mixed research design. The sample of the survey is 85 Pre-Service Integrated Science Teachers (PSIST) selected using a multistage sampling technique from a federal college of education. The instrument for data collection was the Pre-service Integrated Science Teachers Nature of Matter of Test (PSTNMT). The study raised two research questions and tested one hypothesis. The data collected were analyzed using simple frequency counts, analysis of variance and content analysis of responses. The findings of this study indicate that many of the PSIST adopted heuristic reasoning when categorizing matter into elements and compounds. Based on the results of this study, appropriate recommendations were made.
\end{abstract}

\section{Keywords}

Reasoning, Pre-Service Integrated Science Teachers, Matter, Elements, Compounds

\section{Introduction}

The study of misconceptions is one that has occupied a large space and has attracted enormous attention in the field of science education. Research has shown that a science educator cannot ignore misconceptions of students if the ailment affecting students' learning outcomes in science must be diagnosed and addressed (Demircioğlu, Ayas, \& Demircioğlu, 2005). Misconceptions exist in virtually every aspect of human knowledge. The dictionary meaning of misconception 
places it as an idea or a notion that is in incorrect or inaccurate, usually due to a faulty set of thoughts or wrong understanding. Adesoji \& Babatunde (2009) describe misconceptions as erroneous, fallacious or naive conceptions which students hold. Research shows that misconceptions can be difficult to deal with because they impact how students learn new scientific knowledge, play a crucial role in future learning and interfere with acquiring the correct body of knowledge (Nicoll, 2001; Özmen, 2004). Apart from other sources identified in literature such as textbooks and personal experience which sometimes contradicts correct scientific knowledge, misconceptions also arise from interactions with teachers who may or may not hold their misconceptions (Butler, 2014; Wandersee, Mintezes, \& Novak, 1994). Similarly, Kruse \& Roehrig (2005) and Taber \& Tan (2011) established that misconceptions held by teachers are likely to be transferred to the students.

Also, the level of a teacher's content knowledge, as well as the misconceptions they hold, could affect how they teach the concept and how the students would understand it (Yakmaci-Guzel \& Adadan, 2013). Teachers may be aware of misconceptions but may not how they develop or appreciate their impact on the teaching process (Gomez-Zwiep, 2008). Teachers' content knowledge and their conceptions about the topic they teach can enhance or limit students' learning. Constructivism recognizes and admits that prior conceptions held by learners are a factor in the learning process. Therefore, research efforts that will stimulate and build on prospective teachers' conceptions during pre-service training should be the dedication of science educator (Valanides, 2000; Winarno, Widodo, Rusdiana, Rochintaniawati, \& Afifah, 2019). In line with this, there is a call for teachers, including pre-service teachers, to pay close attention to their conceptual understandings of concepts.

Over the years, researchers have examined various topics or concept which many students and teachers (pre-service and in-service) have alternate ideas of in Chemistry. For example Electronegativity (Nicoll, 2001); Chemical equilibrium (Kousathana \& Tsaparlis, 2002; Khairunnisa \& Prodjosantoso, 2020); Chemical bonding, (Ozmen, 2004; Meltafina, Wiji, \& Mulyani, 2019); Electrochemistry (Ceyhun \& Karagolge, 2005; Tien \& Osman, 2017). Inorganic chemistry (Adesoji \& Babatunde, 2009); Diffusion and Osmosis (Tekkaya, 2010); balancing chemical equations (Naah \& Michael, 2012). Nature of matter is a crucial topic in chemistry and misconception held in this topic tends to provide a foundation for misconceptions in other aspects of Chemistry. The particulate nature of matter is perhaps the most investigated and widely reported in the literature (Stojanovska, Soptrajanov, \& Petrusevski, 2012). Particulate nature of matter stands to be one of the most difficult concepts teachers find challenging to understand and teach (Banda, Numba, Chabalengula, \& Mbewe, 2011). Apart from the particulate nature of matter, composition of matter as elements, compounds, and mixture is another aspect of Nature of matter that students usually find difficulty. Yakmaci-Guzel \& Adadan (2013) investigated some pre-service chemistry teachers and found that some of them had some miscon- 
ceptions and lacked a good understanding of the nature of matter. Also, a number of the pre-service teachers had difficulties classifying and distinguishing elements from compounds. In another study, students could not tell the difference between homogeneous and heterogeneous mixtures could not understand the differences between element, compound and mixture and could not choose the right separation methods (Tüysüz, 2009). Conclusions made from the research showed that post-secondary students who offered chemistry seemed to have some difficulty making distinctions between elements, compounds and mixtures when presented with 22 diagrammatic representations of particles (Barker, 2000). In a related study, Harrison \& Treagust (2003) considered the challenges learners have to overcome in understanding the particulate Nature of matter from the microscopic perspective. The findings of Boz (2006) also showed that pupils were unable to provide the right answers when asked open-ended questions related to the nature of matter.

The concept of matter is the core of chemical education, whether at the lower level as integrated science or the upper level as chemistry. Possession of adequate knowledge of Chemistry by a student occupies a central place in his/her understanding of science and level of achievement in it (Abimbade, Akinyemi, Bello, \& Mohammed, 2018). Good understanding of matter provides students with a reliable platform on which the students can learn more complex concepts in chemistry. Matter is all about the world around us; everything that has mass and occupies space. In Nigerian schools, the concept of matter is usually introduced and taught at the junior secondary level by an integrated science teacher. Scholars train integrated science teachers as pre-service teachers to become academically and pedagogically competent to teach the subject in a school. Teaching should embody the specific characteristics of the discipline it represents (Omilani, Ayo-Vaughan, \& Abimbade, 2017). Okanlawon (2014) stresses that if standard teaching concerning professionalism and adequate training is a major contributing factor to quality students' learning outcomes, teacher quality especially at the pre-service level of concern to all stakeholders in education. Teachers can also improve the quality of students learning outcomes by using technologybased resources. "Trainees can benefit from technology mentoring and training to use instructional resources" (Abimbade, Adedoja, Fakayode, \& Bello, 2018). Even though most literature covered the aspect of pre-service teachers in Chemistry and other subjects, little is known by researchers about their counterparts in integrated science in Nigeria. Therefore, this study investigated the difficulty pre-service integrated science teachers have when they are trying to categorize matter into elements and compounds.

Science teacher preparation in colleges of education trains the pre-service teacher in more than one science subject. For example, some pre-service teachers study subject combinations like Physics/Chemistry, Integrated Science/Biology, Integrated Science/Chemistry, just to mention a few. Nature of Matter is a course that is not peculiar to integrated science. All the content of the course also appears in some freshmen Chemistry courses. Therefore it is possible to have a 
complimentary transfer of knowledge gained from Chemistry to the Nature of matter to Integrated Science by students offering both courses. Therefore, this study investigated the pre-service integrated science teachers' misconceptions when categorizing matter into elements and compounds. Also, the subject combination of pre-service integrated science teachers is considered by the researcher as a factor that could influence their misconceptions when classifying matter into elements and compounds. Perhaps those who are combining chemistry with Integrated as their teaching subject will have the edge over those who do not.

\section{Research Questions}

1) What are the misconceptions pre-service integrated science teachers (PSIST) have when classifying matter into elements and compounds?

2) How many PSIST had misconceptions when classifying matter into element and compound?

\section{Hypothesis}

There is no significant main influence of the subject combination of pre-service integrated science teachers' achievement score in PSTNMT.

\section{Methodology}

The action research adopted the ex-po facto research design. The study adopted a multistage sampling technique. The sampled the pre-service integrated science teacher were students offering nature of matter; a second semester 100 level course which is compulsory for all the pre-service science teachers in the department of integrated science in the college. The first author teaches the class.

At the second stage of sampling, the researcher employed a stratified sampling technique. The integrated science (ISC) pre-service teachers were stratified based on their course combination: ISC/Biology, ISC/Chemistry and ISC/Computer. In each of the stratum, ISC/BIO (35), ISC/CHM (25), and ISC/CSC (25) were selected by the researchers.

\section{Instrument}

The instrument for data collection is the Pre-Service Teacher Nature of Matter Test (PSTNMT). The instrument contains sections A and B. The section A is to elicit information on pre-service teachers' level and course combination. Section $B$ includes two major essay questions. The first question is a diagrammatic representation A-E. The instruction required that PSIST classify them into (Element), (Compound), (Mixture of elements), (Mixture of compounds) and (Mixture of elements and compounds).
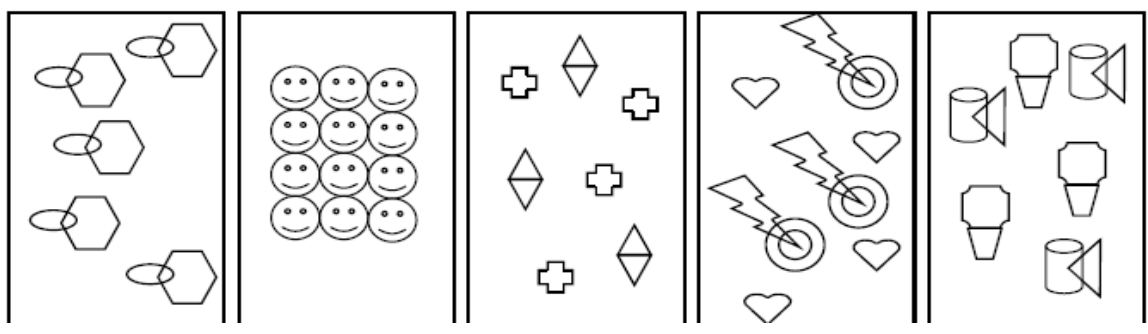
The reliability of the instrument was determined using the test-retest method. The test was administered to 100 level Chemistry students twice with an interval of two weeks. The reliability coefficient of 0.84 Cronbach Alpha was obtained for the instrument by the researcher.

\section{Administration and Scoring of PSTNMT and Scoring}

The researcher administered the instrument to the students a week after the completion of the course nature of matter. The researcher awarded a mark to a correct response, and the maximum obtainable are five marks.

\section{Method of Data Analysis}

The data for this study were analyzed using simple percentage, frequency count, content analysis and Analysis of variance

\section{Results}

\section{Research Question 1}

What are the misconceptions pre-service integrated science teachers have when classifying matter into elements, compounds?

Table 1 showed that pre-service integrated science teachers (PSIST) have misconceptions in classifying matter into elements and compounds. The table indicates that students were able to distinguish between elements and compound based on their responses to diagram A and B. It was more difficult for them to recognize the former than the latter. Some of them classified A or B as a mixture of elements, compounds and compounds and elements. Based on the responses, it is evident that these PSIST lacked the required understanding to recognize a mixture. Diagrams A and B contain homogenous compounds and elements, respectively. So the concept of a mixture is not clear to those who classified A and $\mathrm{B}$ as a mixture.

In the process of classifying $\mathrm{C}, \mathrm{D}$ and $\mathrm{E}$, PSIST were unable to transfer the decision rule which they had employed when classifying the diagrams $\mathrm{A}$ and $\mathrm{B}$ to the classification of diagram $\mathrm{C}, \mathrm{D}$ and $\mathrm{E}$ which are various heterogeneous mixtures of elements and compounds. Based on this, the pre-service integrated science teachers are unable to make a distinction when the diagram represents the combination of basic units (elements and compounds). It means that a diagram must contain just one categorization of matter in the view of the of many of the respondents, for this reason why many PSIST classified diagram C as elements or compounds. These PSIST employed only one decision rule instead of two. The decision rule required for classifying diagrams $\mathrm{C}, \mathrm{D}$ and $\mathrm{E}$ is to: differentiate between elements and compounds and to understand the concept of the mixture. The responses of the PSIST reveals that many of them deduced the decision rule during the reasoning process that preceded their responses (Todd \& Gigerenzer, 2000). This observation may be due to under-generalization of the concepts required for the accurate classification of diagrams $\mathrm{C}, \mathrm{D}$ and $\mathrm{E}$. PSIST in this category are unable to unpack the complexity of the mixtures in the diagrams and solve the problem. 
Table 1. Students' responses to the classification of matter.

\begin{tabular}{ccccccc}
\hline \multirow{2}{*}{ Diagram } & \multicolumn{5}{c}{ Responses of Pre-service Teacher } & \multirow{2}{*}{ Answers } \\
\cline { 2 - 5 } & $\mathrm{C}$ & $\mathrm{E}$ & $\mathrm{ME}$ & MEC & MC & \\
\hline $\mathrm{A}$ & $64(75.3 \%)$ & $14(16.5)$ & $4(4.7 \%)$ & $1(1.2 \%)$ & $2(4.7 \%)$ & $\mathrm{C}$ \\
$\mathrm{B}$ & $10(11.8 \%)$ & $68(80 \%)$ & $5(5.9 \%)$ & $1(1.2 \%)$ & $1(1.2 \%)$ & $\mathrm{E}$ \\
$\mathrm{C}$ & $5(5.9 \%)$ & $2(2.4 \%)$ & $49(57.6 \%)$ & $9(10.6 \%)$ & $20(23.5 \%)$ & ME \\
D & $7(8.2 \%)$ & $1(1.2 \%)$ & $9(10.6)$ & $50(58.8 \%)$ & $18(21.2 \%)$ & MEC \\
E & $3(3.5 \%)$ & & $16(18.8 \%)$ & $20(23.5 \%)$ & $46(54.1 \%)$ & MC \\
\hline
\end{tabular}

On the other hand, those who classified diagram $\mathrm{D}$ wrongly as $\mathrm{MC}$ were aware of the complexity of diagram $\mathrm{D}$ as a mixture using the second decision rule. However, many had used the first decision rule accurately when they classified A and $\mathrm{B}$, and they could not extend it and combine the rules for classifying D. Obviously, the heterogeneous nature of the mixture prevented the PSIST from reasoning appropriately to make decisions. PSIST were unable to differentiate in the complicated situation because they have now reduced the decision rule, which they are to apply. The same also applies to those who classified C wrongly as MEC or MC. Based on these responses, PSIST recognized the heterogeneity of $\mathrm{C}$ but failed to differentiate between the decisions rules appropriate for accurate classification.

\section{Research Question 2}

How many PSIST had misconceptions when classifying matter into element and compound?

Table 1 showed that $64(75.3 \%)$ and $68(80 \%)$ of the PSIST successfully classified diagram A and B correctly. Hence, 21 (24.7\%) and 17 (20\%) of PSIST had misconceptions while classifying diagrams $\mathrm{A}$ and $\mathrm{B}$, respectively.

Table 1 also shows that 49 (57.6\%), 50 (58.8\%) and 46 (54.1\%) PSIST were able to classify C, D and E correctly. Definitely 36 (42.4\%), 35 (41.2\%) and 39 (45.9\%) had misconceptions when classifying C, D and E. The PSIST had difficulty when they need to use more than one decision rule to classify matter.

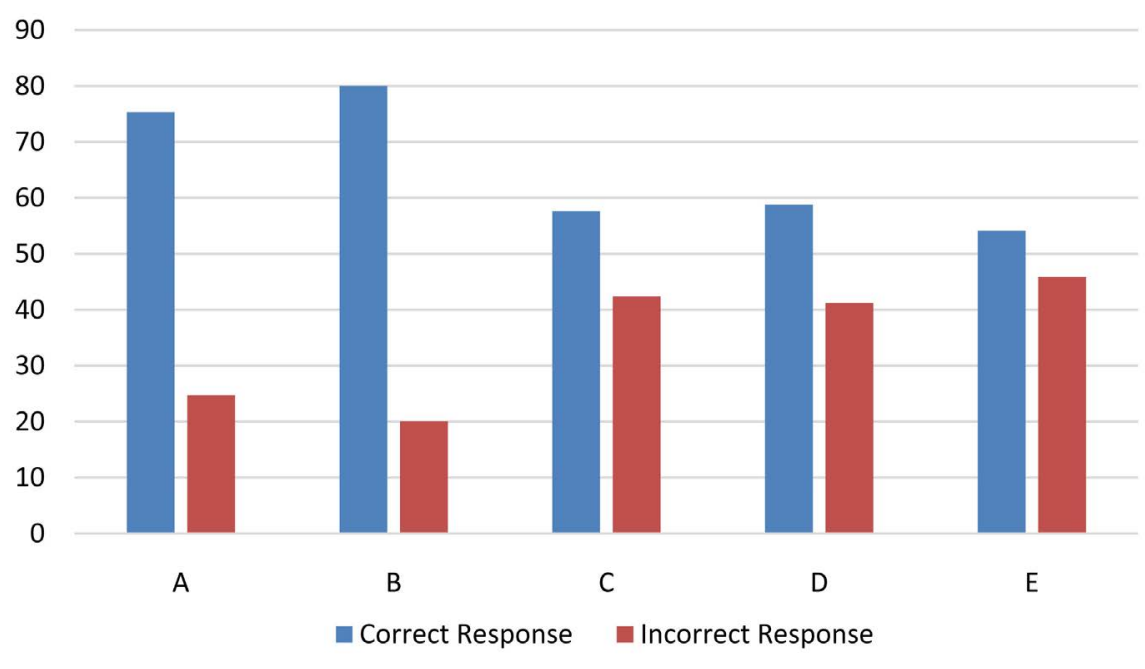


This bar chart shows that many of the PSIST were unable to classify diagrams C, D and E.

\section{Hypothesis}

There is no significant main influence of the subject combination of pre-service integrated science teachers' achievement score in PSTNMT.

Table 2 showed that the course combination of PSIST does not significantly influence their scores in the task of classifying matter $\left(\mathrm{F}_{(2,84)}=0.807: p>0.05\right)$. Therefore the null hypothesis is rejected. The result implies that the course combination does not influence PSIST total sore in the task given.

Although the mean score ISC/CHEM PSIST achievement was the highest (3.5) followed by ISC/COMPUTER (3.2) and ISC/BIOLOGY (3.08) had the least score. The difference observed among all the three groups was not significant.

\section{Discussion}

The findings of this study indicate that pre-service integrated science teachers were unable to classify matter accurately because of their misconceptions. This finding is in line with the findings of Mumba, Chabalengula, \& Banda (2014) that some pre-service science teachers understood the effect of phase change on the size of particles of the matter about the change of state. The misconceptions of the pre-service integrated science teachers about the nature of matter are primarily due to heuristic reasoning. Heuristic reasoning involves using a minimum amount of information and time in the process of decision-making (Boz, 2006; Ugras, 2018). For example, 10.6\% PSIST described diagram C as a mixture

Table 2. Summary of analysis of variance of showing the influence of course combination of the integrated science pre-service teachers and their score in misconception test.

\begin{tabular}{|c|c|c|c|c|c|c|c|c|}
\hline \multicolumn{9}{|c|}{ ANOVA } \\
\hline \multicolumn{9}{|c|}{ Final score } \\
\hline & & \multicolumn{2}{|c|}{ Sum of Squares } & df & \multicolumn{2}{|c|}{ Mean Square } & $\mathrm{F}$ & Sig. \\
\hline \multicolumn{2}{|c|}{ Between Groups } & \multicolumn{2}{|c|}{3.4030} & 2 & \multicolumn{2}{|c|}{1.702} & 0.807 & 0.450 \\
\hline \multicolumn{2}{|c|}{ Within Groups } & \multicolumn{2}{|c|}{172.903} & 82 & \multicolumn{2}{|c|}{2.109} & & \\
\hline \multicolumn{2}{|c|}{ Total } & \multicolumn{2}{|c|}{176.306} & \multicolumn{3}{|l|}{84} & & \\
\hline \multicolumn{9}{|c|}{ Descriptives } \\
\hline \multicolumn{9}{|c|}{ Final score } \\
\hline & \multirow{4}{*}{$\mathrm{N}$} & \multirow{4}{*}{ Mean } & \multirow{4}{*}{$\begin{array}{c}\text { Std. } \\
\text { Deviation }\end{array}$} & \multirow{4}{*}{$\begin{array}{l}\text { Std. } \\
\text { Error }\end{array}$} & \multirow{2}{*}{\multicolumn{2}{|c|}{$\begin{array}{l}\text { 95\% Confidence } \\
\text { Interval for Mean }\end{array}$}} & \multirow{4}{*}{ Minimum } & \multirow{4}{*}{ Maximum } \\
\hline & & & & & & & & \\
\hline & & & & & Lower & Upper & & \\
\hline & & & & & Bound & Bound & & \\
\hline $\mathrm{isc} / \mathrm{csc}$ & 25 & 3.2000 & 1.58114 & 0.31623 & 2.5473 & 3.8527 & 0.00 & 5.00 \\
\hline isc/bio & 35 & 3.0857 & 1.40108 & 0.23683 & 2.6044 & 3.5670 & 0.00 & 5.00 \\
\hline isc/chem & 25 & 3.5600 & 1.38684 & 0.27737 & 2.9875 & 4.1325 & 1.00 & 5.00 \\
\hline Total & 85 & 3.2588 & 1.44875 & 0.15714 & 2.9463 & 3.5713 & 0.00 & 5.00 \\
\hline
\end{tabular}


of elements and compound probably because the diagrams A and B were classified as Element and Compound, respectively. Therefore, they assumed that there should be continuity and the $\mathrm{C}$ will be a mixture of $\mathrm{A}$ and $\mathrm{B}$ without considering the decision rules the earlier employed to classify A and B at all correctly. The heuristic reasoning also manifested when most of the pre-service teachers employed only one decision rule when they were to use two. This finding is in line with the findings of Talanquer (2013) and Talanquer (2013) that many students were unable to perform very well in Chemistry because of various form heuristic thinking such a reduction and overgeneralization. In summary, the findings of this study show that when pre-service integrated science teachers are categorized matter using unconventional assessment method, they show misconceptions. Awan et al. (2011) found that $97.4 \%$ students in high school were unable to categorize the general example and non-examples of daily life in terms of atoms, elements, compound, molecule, ions and mixtures.

The result also showed that no subject combination had an advantage over the other when it comes to classifying matter into elements and mixtures. Contrary to expectation, ISC/Chemistry pre-service teachers did not perform better than other combination. The basis for expectation was that they ISC/CHEM pre-service teacher offered a course with similar content in the department of Chemistry. Although the ISC/chemistry PSIST had the highest mean this is not significantly different from the mean scores of the PSIST in other subject combinations. The ISC/CHEM pre-service teacher performance that taking two courses with similar content on a science concept from different sources might not change the learners' faulty reasoning. This finding is in line with that of Dania \& Daniel (2015) that the course combination of pre-service Physics teachers in colleges of education does not influence their achievement in Physics.

\section{Conclusion}

The study concluded that first-year students in the college of education in the department of integrated science exhibited various forms of faulty reasoning when classifying matter. The concepts of element and compound are the foundations of chemistry at the secondary school level. First-year students had also learned these concepts in secondary school and another first-semester course in chemistry. Hence it is worrisome to find out that the difficulty they have in learning.

\section{Recommendations}

The participants in this study were all science students in the secondary school and learnt mixture atoms, molecule and compound in chemistry. Also, they were exposed to the same concept in one or two courses before the course, which this study considered at a higher level. Irrespective of the repeated learning of the same concept at different levels, the learners retained misconceptions. Perhaps if the assessment were to be the one that requires pre-service teachers to 
supply definitions of the concept, the depth of understanding will not be revealed. Hence, diagrammatic representations and illustrations of the concepts should be part of the teaching and learning process. In addition to this, the assessment of students learning of the concept should be such that discourages rote memorization of definition but encourages critical thinking. It is suggested that science educators and educational technologist design instructional materials for training teachers (pre-service) in such a way that the identification and elimination of misconceptions in science is a possibility.

Furthermore, the pre-service integrated science teacher will teach the nature of matter to students at the basic level of education, the teaching methods class should support and train them on the way to identify and recognize if a student holds any misconceptions about any scientific concept.

\section{Conflicts of Interest}

The authors declare no conflicts of interest regarding the publication of this paper.

\section{References}

Abimbade, O., Adedoja, G. O., Fakayode, B., \& Bello, L. (2018). Impact of Mobile-Based Mentoring, Socio-Economic Background and Religion on Girls' Attitude and Belief towards Antisocial Behaviour (ASB). British Journal of Educational Technology (BJET), 50, 638-654. https://doi.org/10.1111/bjet.12719

Abimbade, O., Akinyemi, A., Bello, L., \& Mohammed, H. (2018). Comparative Effects of an Individualized Computer-Based Instruction and a Modified Conventional Strategy on Students' Academic Achievement in Organic Chemistry. Journal of Positive Psychology and Counseling, 1, 1-19.

Adesoji, F. A., \& Babatunde, A. G. (2009). Investigating Gender Difficulties and Misconceptions in Inorganic Chemistry at the Senior Secondary Level. International Journal of African \& African-American Studies, 7, 1-7.

Awan, S. A., Khan, T. M., Moshin, N. M., \& Doger, A. H. (2011). Students' Misconceptions in Learning Basic Concept Composition of Matter' in Chemistry. International Journal of Applied Science and Technology, 1, 161.

Banda, A., Numba, F., Chabalengula, V. M., \& Mbewe, S. (2011). Teachers Understanding of the Particulate Nature of Matter: The Case of Zambian Pre-Service Science Teacher. Asia-Pacific Forum on Science Learning and Teaching, 12, Article 4.

Barker, V. (2000). Beyond Appearances: Students' Misconceptions about Basic Chemical Ideas: A Report Prepared for the Royal Society of Chemistry. London: Education Division, Royal Society of Chemistry.

Boz, Y. (2006). Turkish Pupils' Conceptions of the Particulate Nature of Matter. Journal of Science Education and Technology, 15, 203-213.

https://doi.org/10.1007/s10956-006-9003-9

Butler, J. (2014). The Investigation of Health Education in the Irish Education System: An Identification of Misconceptions and Knowledge Gaps Relating to Cancer in SecondLevel Students, Pre-Service Teachers and Practicing. Limerick: University of Limerick. https://ulir.ul.ie/handle/10344/4276?show=full

Ceyhun, I., \& Karagolge, Z. (2005). Chemistry Students' Misconceptions in Electrochemistry. Australian Journal of Education in Chemistry, 65, 24-28. 
Dania, C. M., \& Daniel, F. (2015). Influence of Subject Combination and Gender on Achievement of NCE Physics Students in Physics. International Journal of Social Science and Humanities Research, 3, 169-174.

Demircioğlu, G., Ayas, A., \& Demircioğlu, H. (2005). Conceptual Change Achieved through a New Teaching Program on Acids and Bases. Chemical Education Research and Practice, 6, 36-51. https://doi.org/10.1039/B4RP90003K

Gomez-Zwiep, S. (2008). Elementary Teachers' Understanding of Students' Science Misconceptions: Implications for Practice and Teacher Education. Journal of Science Teacher Education, 19, 437-454. https://doi.org/10.1007/s10972-008-9102-y

Harrison, A. G., \& Treagust, D. F. (2003). The Particulate Nature of Matter: Challenges in Understanding the Submicroscopic World. Science \& Technology Education Library, 17, 189-212. https://doi.org/10.1007/0-306-47977-X 9

Khairunnisa, K., \& Prodjosantoso, A. K. (2020). Analysis of Students Misconception in Chemical Equilibrium Material Using Three Tier Test. JTK (Jurnal Tadris Kimiya), 5, 71-79. https://doi.org/10.15575/jtk.v5i1.7661

Kousathana, M., \& Tsaparlis, G. (2002). Students' Errors in Solving Numerical Chemical-Equilibrium Problems. Chemical Education Research and Practice, 3, 5-17. https://doi.org/10.1039/B0RP90030C

Kruse, R. A., \& Roehrig, G. H. (2005). A Comparison Study: Assessing Teachers' Conceptions with the Chemistry Concept Inventory. Journal of Chemical Education, 77, 12461251. https://doi.org/10.1021/ed082p1246

Meltafina, M., Wiji, W., \& Mulyani, S. (2019). Misconceptions and Threshold Concepts in Chemical Bonding. Journal of Physics: Conference Series, 1157, Article ID: 042030. https://doi.org/10.1088/1742-6596/1157/4/042030

Mumba, F., Chabalengula, V. M., \& Banda, A. (2014). Comparing Male and Female PreService Teachers' Understanding of the Particulate Nature of Matter. Journal of Baltic Science Education, 13, 821-827.

Naah, B. M., \& Michael, J. S. (2012). Student Misconceptions in Writing Balanced Equations for Dissolving Ionic Compounds in Water. Chemistry Education Research and Practice, 13, 186-194. https://doi.org/10.1039/C2RP00015F

Nicoll, G. (2001). A Report of Undergraduates' Bonding Misconceptions. International Journal of Science Education, 23, 707-730. https://doi.org/10.1080/09500690010025012

Okanlawon, A. E. (2014). Nigerian Pre-Service Science Teachers' Self-Perceptions of Acquired Pedagogical Knowledge and Skills after Teaching Practice Exposure. Bulgarian Journal of Science and Education Policy (BJSEP), 8, 106-128.

Omilani, N. A., Ayo-Vaughan, A. F., \& Abimbade, O. A. (2017). Teachers' Oversight of Science Values That Promotes Effective Citizenship. International Journal of Education, Culture and Society, 2, 88-93. https://doi.org/10.11648/j.ijecs.20170203.12

Özmen, H. (2004). Some Students' Misconceptions in Chemistry: A Literature Review of Chemical Bonding. Journal of Science Education and Technology, 13, 147-159. https://doi.org/10.1023/B:JOST.0000031255.92943.6d

Stojanovska, M. I., Soptrajanov, B. T., \& Petrusevski, V. M. (2012). Addressing Misconception about the Nature of Matter among Secondary School and High School Students in the Republic of Macedonia. Creative Education, 3, 619-631.

https://doi.org/10.4236/ce.2012.35091

Taber, K. S., \& Tan, K. C. D. (2011). The Insidious Nature of Hard-Core Alternative Conceptions: Implications for the Constructivist Research Programme of Patterns in High School Students' and Pre-Service Teachers' Thinking about Ionization Energy. International Journal of Science Education, 33, 259-297. 
https://doi.org/10.1080/09500691003709880

Tekkaya, C. (2010). Remediating High School Students' Misconceptions Concerning Diffusion and Osmosis through Concept Mapping and Conceptual Change Text. Research in Science \& Technological Education, 21, 5-16.

https://doi.org/10.1080/02635140308340

Tien, L. T., \& Osman, K. (2017). Misconceptions in Electrochemistry: How Do Pedagogical Agents Help? In Overcoming Students' Misconceptions in Science (pp. 91-110). Singapore: Springer. https://doi.org/10.1007/978-981-10-3437-4 6

Todd, P. M., \& Gigerenzer, G. (2000). Précis of Simple Heuristics That Make Us Smart. The Behavioral and Brain Sciences, 23, 727-741. https://doi.org/10.1017/S0140525X00003447

Tüysüz, C. (2009). Development of Two-Tier Diagnostic Instrument and Assess Students' Understanding in Chemistry. Scientific Research and Essay, 4, 626-631.

Ugras, M. (2018). Heuristic Reasoning of Pre-Service Science Teachers in Chemistry Topics. Journal of Baltic Science Education, 17, 343.

Valanides, N. (2000). Primary Student Teachers' Understanding of the Particulate Nature of Matter and Its Transformations during Dissolving. Chemistry Education. Research and Practice in Europe, 1, 249-262. https://doi.org/10.1039/A9RP90026H

Winarno, N., Widodo, A., Rusdiana, D., Rochintaniawati, D., \& Afifah, R. M. A. (2019). Pre-Service Science Teachers' Conceptual Understanding of Integrated Science Subject: A Case Study. Journal of Physics: Conference Series, 1204, Article ID: 012104. https://doi.org/10.1088/1742-6596/1204/1/012104

Yakmaci-Guzel, B., \& Adadan, E. (2013). Use of Multiple Representations in Developing Pre-Service Chemistry Teachers' Understanding of the Structure of Matter. International Journal of Environmental and Science Education, 8, 109-130. 